\title{
Using Technology Acceptance Model to Predict Lecturers' Acceptance of Moodle: Case of Botswana University of Agriculture and Natural Resources
}

\author{
Moakofhi Kago Moakofhi, Tawona Vanessa Phiri, Oratile Leteane, Enock Bangomwa \\ BUAN \\ Botswana
}

\begin{abstract}
The use of technology to enhance learning is regarded as significant among educational institutions due to continuous improvements of the Internet and other communication technologies. The Botswana University of Agriculture and Natural Resources (BUAN), like many other academic institutions, is undergoing reforms in its education processes in response to these technological effects on higher education. One such reform is an attempt at introducing e-learning and learning management systems. The purpose of this study was to subject BUAN lecturers to the Technology Acceptance Model (TAM), a well-established theoretical model, to predict their acceptance level of Moodle. A quantitative research approach was used to conduct the survey with a questionnaire used to collect required data from 50 BUAN lecturers who volunteered to participate. The results revealed that participants perceived Moodle easy to use hence consider that it will be useful in their working environment. This study confirmed TAM to be a useful theoretical model in helping to understand and explain behavioural intention to use Moodle. As has been widely argued in literature that TAM is effective in predicting the acceptance of technology, the results of this study demonstrated that TAM is effective in predicting the possibility of acceptance of Moodle by BUAN lecturers. The researchers argue that, based on the results from this study, Moodle should be fully implemented at BUAN in order to facilitate the teaching and learning process.
\end{abstract}

\section{Introduction}

It is hard to think of the 21 st century's teaching and learning process without linking it with Information and Communication Technologies (ICTs). ICTs are now utilised in all aspects of education, from data collection, information processing to knowledge creation and knowledge retention. The use of ICTs in education is prevalent in course management and instructional components. This is made possible by the use of e-learning systems. These platforms provide many capabilities, such as interaction, collaboration, conversation, feedback and networking. Furthermore, nowadays higher education learners are becoming more diverse and they demand a transformative form of education. According to [1], these students, the Net Generation, learn better through discovery than being told what to do. Learning Management Systems (LMSs), such as Moodle (Modular Object-Oriented Dynamic Learning Environment) - an open source e-learning system - help in achieving this.

Currently, Botswana University of Agriculture and Natural Resources (BUAN) does not have a fully functional e-learning platform in place. However, it uses a depository popularly referred to as 'student drive' [1], which lacks collaboration, interaction and feedback aspects. BUAN is now looking at acquiring an interactive learning tool that promotes student engagement and interaction, to keep up with developments in the educational sphere. In order for an e-learning platform to be effective, the technology must actually be used. In that context, BUAN lecturers will have to accept and use the envisaged LMS for it to succeed. According to [2], new systems often fail because end-users do not accept them, either because they do not see these systems as beneficial to them, or because they are too complex and not easy to deal with.

This paper investigates the acceptance level of BUAN lecturers in infusing Moodle in their teaching. In order to achieve this, Technology Acceptance Model (TAM) is used as a theoretical basis for predicting lecturers' acceptance of this LMS. In order words, this study examined TAM under an academic setting at BUAN to investigate lecturers' possible acceptance of e-learning technology. The research discussed in this paper was guided by the following question: If Moodle was to be introduced at BUAN, will lecturers accept and subsequently use it? That is, do BUAN lecturers' attitudinal beliefs such as perceived ease of use and perceived usefulness of Moodle predict its adoption? This question is explored with the use of TAM. Hence the main purpose of this study was to use TAM to assess the possibility of acceptance of Moodle by BUAN lecturers, and provide a wellsupported prediction of whether it will be utilised in the teaching and learning environment at BUAN. 
The paper is organised as follows: section 2 covers the theoretical background and summary of literature review on e-learning acceptance and adoption. It also focus on the research model and discusses hypotheses. Section 3 discusses the research methodology that was used for this study. In section 4, the results are analysed and discussed. Lastly, section 5 concludes the paper with implications and limitations, and also offers recommendations.

\section{Literature Riview}

In this section, e-learning platforms, and Moodle in particular, are discussed. Technology Acceptance, the theoretical model that was used to predict the acceptance of Moodle by BUAN lecturers, is also discussed here. Lastly, a review of previous studies that applied TAM to predict users' acceptance of technology is done.

\subsection{E-learning platforms}

Many definitions of e-learning have been offered, but central to them is the use of the computer, digital media and communication technologies in education. This is learning where ICTs are utilised to access educational materials outside a traditional classroom. [3] sees e-learning as a form of education that is facilitated by the Internet and ICTs, and that "encompasses the use of the World Wide Web to support instruction and to deliver course content" ( $p$. 2). In e-learning systems, students can access course contents in different formats such as sound, text, images, and interact with their colleagues and teachers through chat rooms, message boards, forums, video-conferencing and/or other types of communication tools [4]. In this case, teaching is supported by the computer, Internet, mobile phones, LMSs and so forth. This paper adopts the definition offered by [5], that e-learning is where educational services that are necessary for handling all aspects of a course are provided through 'a single, intuitive and consistent web interface' (p. 91).

E-learning offers many benefits and has a positive impact on student performances hence many higher education institutions have adopted it. For developing nations like Botswana, one such benefit is the reduction in costs associated with education. According to [6], use of technology in education removes geographical barriers and enables everybody to learn whenever and wherever without the presence of a teacher. Thus, since face - to - face interaction is not a requirement in e-learning, elearning becomes more suited to other challenges faced by developing countries, such as poor road systems which make transporting learners from remote rural areas difficult [7]. This makes it possible for learners to receive class notes and information, take assessments, and communicate anywhere and anytime when the need arises.

The aim of e-learning is to make education accessible and reduce costs and time as well as improve learner's academic performance. As a result, educational institutions are interested in LMSs that can systematically implement and manage elearning. However, there are many LMS to choose from, some representing commercial solutions (such as WebCT, Clix and Blackboard) and others opensource solutions (such as OLAT and Moodle). Currently, Blackboard (commercial) and Moodle (open-source) are the dominant LMSs used to support and promote e-learning [8]. Several studies, such as [9] and [10], have identified Moodle as the most used open-source solution in higher education. [10] identified Moodle as a highly preferred tool at the University of Botswana's department of computer science.

Regardless of the type, in order for users to fully utilise these LMSs, they will have to accept and adopt them. In view of the amount of money and resources spent by educational institutions in implementing e-learning systems, such systems will be of little use if end users fail to fully utilise them.

2.1.1. Moodle. Moodle is a free open Course Management System (CMS) which higher education institutions, individuals and businesses can integrate Web to their courses. It allows the creation of a website and restricts access to enrolled students only. Under Moodle, learners can communicate and collaborate in a synchronized way (through chats) as well as through asynchronous communication (discussion forums). This allows learners who are geographically dispersed to exchange information. This e-learning platform offers a common place for students to go for many classroom resources. It has configurable features that allow for posting news items, creation of assessment processes (assignments, quizzes, surveys, and online tests), posting of electronic journals and resources, managing tasks through a timetable, and more. The goal of Moodle is to provide a set of tools that supports discovery-based approach to e-learning and drive the creation of an environment that allows for collaborative interaction among students.

Moodle provides two different set of functionalities: resources and modules. According to [4], resources are instructional material created using digital formats and later uploaded into the tool. Examples of resources are PowerPoint files, Word documents, video files and Web pages. Modules on the other hand are materials created through Moodle so that there could be interaction among users when manipulating and transforming content. Examples of modules are assignments, chats, quizzes, wikis and surveys [4]. These resources, modules and activities are the ones that make Moodle to be configurable, 
highly flexible and feature rich. Flexibility is the ability to (a) easily upload and download learning content and related resources in and out of LMS, and (b) customize applications to meet specific needs of users

\subsection{Technology Acceptance Model}

The theoretical framework for this study was the Technology Acceptance Model. TAM is a model popularly known to be used to check possible acceptance of technology. It was first created by Fred Davis and Richard Bagozzi [11]. It tries to explain why people would choose to use a particular technology in a work context. TAM states that they do so because they find the technology useful for their work and easy to use. [11] proposed TAM to explain the casual links between beliefs (usefulness of a system and ease of use of system) and users' attitudes, intentions, and actual usage of the system. Thus, TAM proposes that user's beliefs are predictors of user attitude towards using the technology, behavioral intentions to use and actual usage. The original TAM is shown in Figure 1. TAM concepts are:

- Perceived Usefulness (PU) - the degree to which a potential user believes that using the technology would enhance his or her work performance,

- Perceived Ease of Use (PEOU) - how effortless a potential user believes using the technology will be,

- Attitude Toward Using (ATU) - a potential user's positive or negative feeling associated with performing a specific behaviour, and

- Behavioral Intention to Use (BI) - the degree to which a potential user has formulated conscious plans to perform or not perform some specified future behaviour.

Both PU and PEOU are considered distinct direct determinants of ATU, hence they are affected directly by system design. TAM further proposes that PEOU influences PU, and PU directly affects BI. Finally, the user's attitudes towards using the technology determines the behavioural intentions to use the technology. BUAN has not started using Moodle yet, so the research model employed in this study (see Figure 2) excluded actual system use. External factors considered were age, gender, academic qualification and teaching experience.

Several studies have applied TAM as a ground theory to efficiently explain and predict the acceptance of technology. It was used to investigate acceptance of healthcare [12], email [13], World Wide Web [14], search engines [15], mobile banking [16] and many others. When TAM is applied in education, literature shows mixed results on the impact of the different TAM constructs on technology acceptance.

TAM was used by [2] in a survey on lecturers' attitudes towards Moodle in a Jordanian university. From the findings, only $18.8 \%$ of the participants believed that it will be easy to upload teaching and learning materials into Moodle, while $27.5 \%$ believe it will be a lot of work thus not easy. Here PEOU was found not to be a significant predictor of intention to use Moodle. This is consistent with findings from a study by [17], that showed PEOU did not have a significant influence on student attitude or intentions towards using Internet-based learning medium.

PEOU was found to have a significant effect on intention to use and on attitudes to use in a study conducted by [18]. They surveyed exploring students' acceptance of e-learning using TAM, and in their findings students who find e-learning system easy to use could clarify this and may find the system useful. The findings also revealed that PU has significant effect on intention to use but not on attitudes to use. This may be because it was found that in their willingness to adopt e-learning system students were only driven by its benefits.

[19] showed PU to be a significant positive influence on student teachers' attitude towards computer use and behavioural intention. Moreover, PEOU was found to significantly influence PU, and attitude towards computer use to influence behavioural intention. In [20]'s study that investigated the perceived convenience in acceptance of English mobile learning using TAM, attitude towards use was significantly influenced by both PU and PEOU. Furthermore, PU and attitude towards using were found to have a direct influence on continuance of intention to use. Overall, their extended TAM was effective at predicting and explaining the acceptance of mobile learning.

\subsection{Study Hypotheses}

Existing literature shows that PEOU is a positive determinant of PU (e.g. [5] and [17]), therefore the following hypothesis is proposed:

\section{H1: PEOU will have a positive effect on the PU.}

Many studies also show that both PU and PEOU are significant determinants of attitude to use a system (e.g [3], [2] and [5]), so the researchers propose the following hypotheses:

H2: PU will have a positive effect on BUAN lecturers' attitudes towards using Moodle.

H3: PEOU will have a positive effect on BUAN lecturers' attitudes towards using Moodle. 


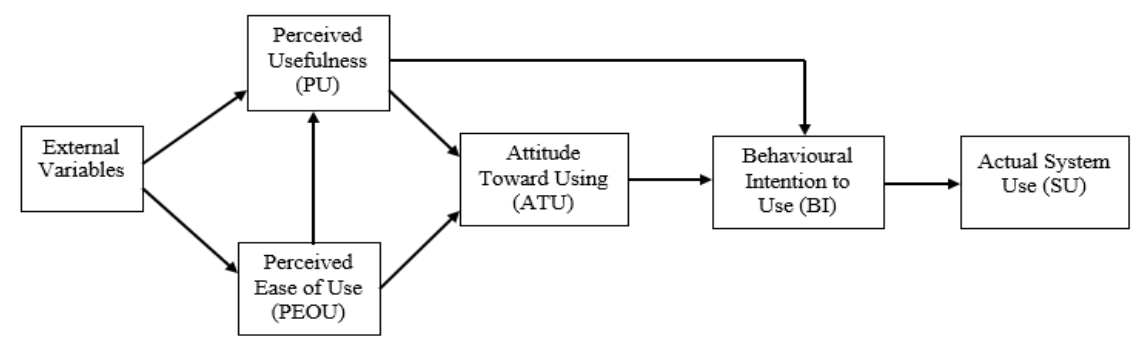

Figure 1. Original Technology Acceptance Model [11]

As reported by [17], PU is the most important predictor of intention to use a system. According to [5] PEOU has also influenced intention to use a technology. Therefore, the following hypotheses are proposed:

H4: PU will have a positive effect on BUAN lecturers' intention to use Moodle.

H5: PEOU will have a positive effect on BUAN lecturers' intention to use Moodle.

Several other studies have demonstrated that attitude towards using a system is a direct determinant of behavioural intention to use technology (e.g.: [5], [3] and [2]). Therefore, the following hypothesis is proposed:

H6: ATU will have a positive effect on BUAN lecturers' intention to use Moodle.

Taking the above hypotheses into consideration, this study's research model was proposed as shown in Figure 2.

\section{Research Methodology}

To test the six (6) stated hypotheses a quantitative survey was performed. This section discusses this survey in terms of the development of the data collection instrument, the sampling process, data collection and analysis approach used.

A paper-based questionnaire was used to collect data from the study's test subjects, who were BUAN lecturers. The questionnaire was developed on the basis of the literature review. In order to reduce the measurement error, the questionnaire was developed as follows: First, a pre-test of the questionnaire was performed. The main goal of the pre-test was to improve the content of the measuring items, hence the questionnaire was given to two BUAN lecturers from, one from Statistics Unit and another one from the Educational Technology Unit, to improve face and content validity. From feedback gotten from the pre-test, wording was refined for some few items. Next stage, a pilot test of the study was performed with 12 BUAN lecturers (2 each from the university's 6 lecturers departments) who were not part of the sample. The main purpose of the pilot test was to empirically check whether or not the questionnaire lacked accuracy or precision. The test re-test procedure of reliability measurement was used. In this procedure, the same instrument was administered on two different occasions to the same individual and the responses correlated. The pilot test results confirmed a solid reliability for all measurement items. The questionnaire consisted of the following sections:

Section A - characterisation of the participants in terms of age, gender, academic qualification and teaching experience.

Section B - consisted of questions formulated based on knowledge and usage of ICT.

Section C - consisted of questions that sought opinions on possibility of acceptance of Moodle. The questions in this section were organized according to the TAM constructs of PEOU, PU, ATU and BI, adapted in the context of Moodle.

Questions in sections B and C were structured using a five-point Likert-type scale designed as follows: 1 = Strongly Agree, 2 = Agree, $3=$ Neutral, $4=$ Disagree and $5=$ Strongly Disagree. The participants were asked to rate their level of agreement to closed questions using this scale. A copy of the questionnaire can be obtained by email from the authors.

The estimated number of lecturers at BUAN is 100 and the researchers wanted a study population of sixty (60); ten lecturers from each of the six academic departments. This sample size represents $60 \%$ of the total population. Due to several reasons, only fifty (50) lecturers participated in the study. A simple random sampling was used to select the 50 participants. Simple random selection without replacement was used and it allowed the researchers to decide who to sample based on the problem under study. Simple random sampling was then carried out in all the 6 lecturers departments to pick at most 10 participants. The researchers sought the permission from Dean of Faculty of Agriculture to administer questionnaires. The researchers also sought the 


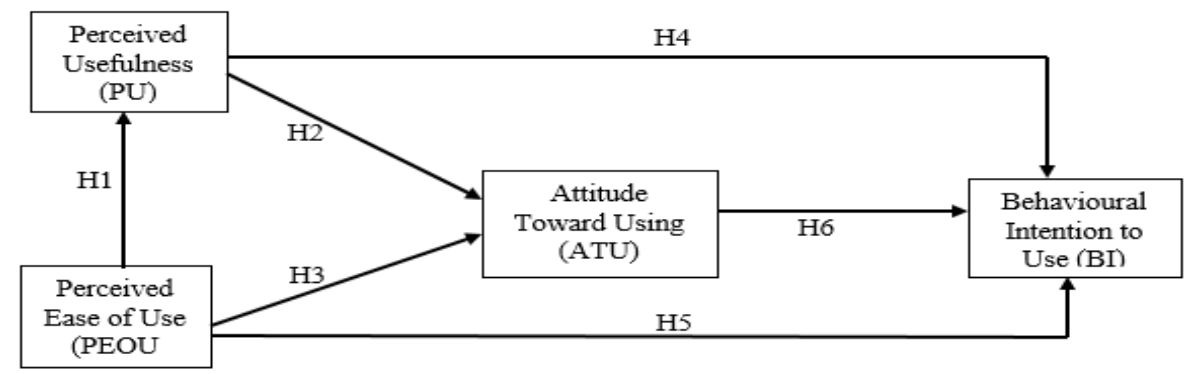

Figure 2: The Research Model

consent of the research participants. As such, requests for participation in the survey was sent to the selected lecturers through the office of the Dean of Faculty of Agriculture. Participants were assured of confidentiality for their responses and that they were not to write anything on the questionnaires that would reveal their identities. There is always a possibility of a sampling frame error due to selfselection of participants in the study, and only those that were interested responded, hence 50 participants instead of 60 .

The questionnaires were self-administered by the researchers to collect data. This allowed personal contact between researchers and participants for the researchers to fully explain the purpose of the study. Moodle is not yet implemented at BUAN, so the researchers set up a trial of Moodle in one of the university computers and asked participants for both the pilot and main study to log onto Moodle and explore it before answering questions. This was so that they could atleast have some appreciation of Moodle. The questionnaires were collected after seven (7) days. All the questionnaires were returned and deemed useful for analysis because there were no cases of missing data. This gave a response rate of $100 \%$. After data was collected, it was fed into an Excel spreadsheet (2013 version) and organised before being imported to the Statistical Package for the Social Sciences (SPSS) version 2023. Excel was used to analyse data on participants' Moodle knowledge and usage. SPSS was used to test the relationship between TAM's constructs. Pearson's correlation method and regression tests were conducted to evaluate the strength of the relationships between these constructs. Descriptive statistics were used to summarise and interpret the data collected from the participants. These statistics included frequencies, means and the spread of data measured through standard deviations.

\section{Results Presentation, Analysis and Discussion}

\subsection{Demographic Characteristics}

Looking at the participants' demographic profiles as shown in Table 1, responses were received from
33 males and 17 females, giving $66 \%$ and $34 \%$ respectively. The average age of participants was 45.9 years old, being minimum 30 years old and maximum 59 years old. The university requires a minimum qualification of Masters' degree for a lecturer. As can be seen from Table 1, majority of participants have a doctoral degree $(60 \%)$. In terms of tertiary teaching experience, majority of the participants have been teaching for 16 to 20 years. Thus, according to Table 1, a typical lecturer at BUAN is a male of 41 to 50 years, with tertiary teaching experience of 16 to 20 years and holding a doctoral degree.

\subsection{ICT Usage}

The results captured in Table 2 show that all participants have computer access at the university and all upload notes on the student portal. Although $96 \%$ of participants communicate academic work with their colleagues through email, only $78 \%$ use email to communicate academic work with students. $86 \%$ of participants reported to have social media access and $76.7 \%$ use social media to present academic to their students. A bigger number of participants $(88.4 \%)$ reported to communicate academic work with colleagues through social media. Majority $(92 \%)$ of participants use PowerPoint to teach and only $24 \%$ use interactive boards available in the university. Lastly, only $8 \%$ of participants reported to have used Moodle before this study. These results show that the BUAN has technology that lecturers use to communicate with colleagues and students, but that do not utilise the interactive technology available. The results also indicate that lecturers have had minimal contact with Moodle as they report to have never used it before this study.

\subsection{Moodle Usage}

Results in Table 2 also shows that participants have not used Moodle before this study, hence did not know how to start Moodle page. This is backed by the negative response rates of $72 \%$ and $74 \%$ respectively. Nevertheless, after participants interacted with the Moodle trial that was set up for 
Table 1. Profiles of the Participants

\begin{tabular}{|c|c|c|c|}
\hline \multicolumn{2}{|l|}{ Characteristics } & Frequency & $\begin{array}{c}\text { Percentage } \\
(\%)\end{array}$ \\
\hline \multirow{2}{*}{ Age } & Below 31 years old & 2 & 4 \\
& $31-40$ years old & 8 & 16 \\
& $41-50$ years old & 23 & 46 \\
& Above 50 years old & 17 & 34 \\
\hline \multirow{2}{*}{ Gender } & Male & 33 & 66 \\
& Female & 17 & 34 \\
\hline \multirow{2}{*}{ Academic Qualification } & & 20 & \\
& Master's Degree & 30 & 40 \\
\hline & Doctoral Degree & & \\
\hline & & 11 & 22 \\
Tertiary Teaching & Below 6 years & 4 & 8 \\
Experience & $6-10$ years & 4 & 8 \\
& $11-15$ years & 21 & 42 \\
& $16-20$ years & 10 & 20 \\
\hline
\end{tabular}

Table 2. ICT Integration and Moodle usage

\begin{tabular}{|c|c|c|c|c|}
\hline & ICT Usage & Frequency & $\begin{array}{l}\text { Yes } \\
(\%)\end{array}$ & $\begin{array}{l}\text { No } \\
(\%)\end{array}$ \\
\hline $\mathbf{1}$ & Do you have access to a computer at university? & 50 & 100 & 0 \\
\hline 2 & $\begin{array}{l}\text { Do you upload learning material on the student portal (student } \\
\text { drive)? }\end{array}$ & 50 & 100 & 0 \\
\hline 3 & $\begin{array}{l}\text { Do you communicate academic work with students through } \\
\text { email? }\end{array}$ & 50 & 78 & 22 \\
\hline 4 & $\begin{array}{l}\text { Do you communicate academic work with colleagues through } \\
\text { email? }\end{array}$ & 50 & 96 & 4 \\
\hline 5 & $\begin{array}{l}\text { Are you on social media? e.g Facebook, Twitter, Instagram. } \\
\text { etc. }\end{array}$ & 50 & 86 & 14 \\
\hline 6 & $\begin{array}{l}\text { Do you communicate academic work with students through } \\
\text { social media? }\end{array}$ & 43 & 76.7 & 23.3 \\
\hline 7 & $\begin{array}{l}\text { Do you communicate academic work with colleagues through } \\
\text { social media? }\end{array}$ & 43 & 88.4 & 11.6 \\
\hline 8 & Do you use PowerPoint to teach? & 50 & 92 & 8 \\
\hline 9 & Do you use interactive boards available on the university? & 50 & 24 & 76 \\
\hline \multirow[t]{2}{*}{10} & It is my first time to use Moodle platform & 50 & 92 & 8 \\
\hline & Moodle Usage & & & \\
\hline $\mathbf{1}$ & I have knowledge about Moodle & 50 & 28 & 72 \\
\hline 2 & I have the ability to start Moodle page & 50 & 26 & 74 \\
\hline 3 & I know the best way to use Moodle & 50 & 88 & 12 \\
\hline 4 & $\begin{array}{l}\text { I know how I will stimulate students to communicate through } \\
\text { Moodle }\end{array}$ & 50 & 70 & 30 \\
\hline 5 & I know how I will use Moodle share ideas from other educators & 50 & 66 & 34 \\
\hline 6 & I know how to use Moodle to learn from other educators & 50 & 68 & 32 \\
\hline
\end{tabular}

this study, $88 \%$ believed they will know the best way of using Moodle, which they believe will simulate communication and sharing of ideas between themselves and students. These results indicate that, although BUAN lecturers have little knowledge about Moodle, after their interaction with and appreciation of the platform, they believe it will be useful in their duties and add the interaction part which they have been missing when using available technology to communicate with colleagues and students.

\subsection{Results of TAM Correlation Analysis on Hypotheses Testing}

Testing the relationships of TAM's variables helped in examining the validity of the hypotheses given. It also helped in evaluating the strength of these relationships. Table 3 below provides a summary of this analysis.

A significant positive relationship was found between Perceived Ease of Use and Perceived Usefulness, and this supports the hypothesis H1 ( ignificant level $=0.805$ ). Thus, the hypothesis was retained: 


\section{H1: PEOU will have a positive effect on the PU.}

The results also indicate that there is a statistically sufficient evidence regarding the impact of Perceived Usefulness on the attitude of BUAN lecturers to use Moodle. This is shown by support for $\mathrm{H} 2$ (correlation coefficient $=0.711)$, hence the hypothesis was accepted.

H2: PU will have a positive effect on BUAN lecturers' attitudes towards using Moodle.

The results also provide support for a significant relationship between Perceive Ease of Use and BUAN lecturers' attitude towards using Moodle. This means the results support hypothesis H3 (correlation coefficient $=0.783$ ).

H3: PEOU will have a positive effect on BUAN lecturers' attitudes towards using Moodle.

Hypothesis $\mathrm{H} 4$ is also supported by the results as they show a statistically significant relationship between Perceived Usefulness and BUAN lecturers' intention to use Moodle. This is at 0.622 correlation coefficient. Thus, hypothesis $\mathrm{H} 4$ is retained.

H4: PU will have a positive effect on BUAN lecturers' intention to use Moodle.

The data also indicate support for hypothesis H5. The results show a significant positive relationship between Perceived Ease of Use and BUAN lecturers' intention to use Moodle. This is at 0.673 correlation coefficient. Thus, hypothesis H5 is retained:

H5: PEOU will have a positive effect on BUAN lecturers' intention to use Moodle.

Lastly, there is statistical evidence to support hypothesis H6. The results show a significant positive relationship between BUAN lecturers' attitude to use Moodle, and their intentions to use Moodle. This support of hypothesis H6 is shown by 0.805 correlation coefficient. Thus, the hypothesis is retained:

H6: ATU will have a positive effect on BUAN lecturers' intention to use Moodle.

To know the degree of possible acceptance of Moodle by BUAN lecturers, and a deeper understanding of participants' perceptions of TAM variables investigated in this study, they are discussed below.

\subsection{Perception of Usefulness of Moodle}

Perceived usefulness refers to the lecturers' beliefs that Moodle will enhance their job performance [2]. For a richer understanding of participants' perceptions on the usefulness of Moodle, statistical analysis in terms of frequencies and percentages is shown in Table 4 below. The participants used a 5 Likert scale (i.e. $1=$ Strongly Agree, $2=$ Agree, $3=$ Neutral, $4=$ Disagree and $5=$ Strongly Disagree) to rate their level of agreement on 7 statements about Perception of Usefulness of Moodle. Participants agree with all the statements, with none of them disagreeing that Moodle will be useful for their work. Of the 7 statements the top 3 are; (1) PU7 (96\% of participants both agree and strongly agree, with mean of 1.64), (2) PU1 (94\% of participants both agree and strongly agree, with mean of 1.64), and (3) PU6 (76\% of participants agree and strongly agree, with mean of 2.10). These results indicate a high confidence level by BUAN lecturers that Moodle will be useful in executing their duties. The statements in Table 4 are described as follows:

PU1: Using Moodle will improve the quality of my work

PU2: Using Moodle will give me greater control of my work

PU3: Moodle will increase my job performance

PU4: Using Moodle will reduce the time I spend on unproductive activities

PU5: Moodle will help me accomplish more work that would otherwise be possible

PU6: Moodle will enhance my effectiveness on the job

PU7: Overall Moodle will be useful for my job.

\subsection{Perception of Ease of Use of Moodle}

Perceived ease of use refers to the lecturers' beliefs that Moodle will be effortless to use. The participants again used a 5 Likert scale (i.e. $1=$ Strongly Agree, 2 = Agree, $3=$ Neutral, $4=$ Disagree and $5=$ Strongly Disagree) to rate their level of agreement on 7 statements on perceptions on ease of use of Moodle. The results, in Table 5 below, indicate that $44 \%$ of participants agree that learning to operate Moodle will be easy for them, as compared to only $6 \%$ who say it will not be easy to do so. Operating Moodle means the process of navigating through the platform, login into it and getting the required information [2]. Although participants interacted with the pilot Moodle set up, the time of interaction might not have been enough, as shown by the results of statements PEOU2, PEOU5 and PEOU6, where participants were undecided. During their interaction with the pilot Moodle set up, a lot of functionalities were not 
Table 3. Pearson Correlation Analysis

\begin{tabular}{|c|c|c|c|c|c|c|}
\hline \multicolumn{7}{|c|}{ Correlations } \\
\hline \multicolumn{3}{|c|}{ Control Variables } & PEOU & PU & ATU & $\mathrm{BI}$ \\
\hline \multirow[t]{12}{*}{- none-a } & PEOU & Correlation & 1.000 & .805 & .783 & .673 \\
\hline & & Significance (2-tailed) & & .000 & .000 & .000 \\
\hline & & $\mathrm{df}$ & 0 & 48 & 48 & 48 \\
\hline & PU & Correlation & .805 & 1.000 & .711 & .622 \\
\hline & & Significance (2-tailed) & .000 & & .000 & .000 \\
\hline & & $\mathrm{df}$ & 48 & 0 & 48 & 48 \\
\hline & ATU & Correlation & .783 & .711 & 1.000 & .805 \\
\hline & & Significance (2-tailed) & .000 & .000 & & .000 \\
\hline & & $\mathrm{df}$ & 48 & 48 & 0 & 48 \\
\hline & $\mathrm{Bl}$ & Correlation & .673 & .622 & .805 & 1.000 \\
\hline & & Significance (2-tailed) & .000 & .000 & .000 & \\
\hline & & $\mathrm{df}$ & 48 & 48 & 48 & 0 \\
\hline
\end{tabular}

Table 4. Perceived Usefulness of Moodle

\begin{tabular}{|c|c|c|c|c|c|c|c|c|}
\hline \multirow{2}{*}{ Item } & \multirow{2}{*}{ Mean } & \multirow{2}{*}{$\begin{array}{l}\text { Standard } \\
\text { Deviation }\end{array}$} & \multicolumn{7}{|c|}{ Response \% } & \multirow{2}{*}{ Scale } \\
\cline { 4 - 8 } & & & $\begin{array}{l}\text { Strongly } \\
\text { Agree }\end{array}$ & Agree & Neutral & Disagree & $\begin{array}{l}\text { Strongly } \\
\text { Disagree }\end{array}$ & \\
\hline PU1 & 1.64 & 0.78 & 48 & 46 & 0 & 6 & 0 & Agree \\
\hline PU2 & 2.40 & 0.93 & 12 & 52 & 22 & 12 & 2 & Agree \\
\hline PU3 & 2.28 & 0.99 & 20 & 48 & 18 & 12 & 2 & Agree \\
\hline PU4 & 2.38 & 1.03 & 20 & 40 & 24 & 14 & 2 & Agree \\
\hline PU5 & 2.20 & 0.76 & 16 & 52 & 28 & 4 & 0 & Agree \\
\hline PU6 & 2.10 & 0.74 & 18 & 58 & 20 & 4 & 0 & Agree \\
\hline PU7 & 1.64 & 0.56 & 40 & 56 & 4 & 0 & 0 & Agree \\
\hline
\end{tabular}

Table 5. Perceived Ease of Use of Moodle

\begin{tabular}{|c|c|c|c|c|c|c|c|c|}
\hline \multirow{2}{*}{ Item } & \multirow{2}{*}{ Mean } & \multirow{2}{*}{$\begin{array}{l}\text { Standard } \\
\text { Deviation }\end{array}$} & \multicolumn{7}{|c|}{ Response \% } & \multirow{2}{*}{ Scale } \\
\cline { 5 - 8 } & & & $\begin{array}{l}\text { Strongly } \\
\text { Agree }\end{array}$ & Agree & Neutral & Disagree & $\begin{array}{l}\text { Strongly } \\
\text { Disagree }\end{array}$ & \\
\hline PEOU1 & 1.98 & 0.87 & 32 & 44 & 18 & 6 & 0 & Agree \\
\hline PEOU2 & 2.48 & 0.91 & 16 & 32 & 40 & 12 & 0 & Neutral \\
\hline PEOU3 & 1.56 & 0.58 & 48 & 48 & 4 & 0 & 0 & Agree \\
\hline PEOU4 & 1.66 & 0.59 & 40 & 54 & 6 & 0 & 0 & Agree \\
\hline PEOU5 & 2.72 & 0.88 & 8 & 32 & 40 & 20 & 0 & Neutral \\
\hline PEOU6 & 2.62 & 0.92 & 10 & 38 & 32 & 20 & 0 & Neutral \\
\hline PEOU7 & 1.82 & 0.60 & 28 & 62 & 10 & 0 & 0 & Agree \\
\hline
\end{tabular}

Table 6. Attitudes Toward Using and Behavioural Intention to Use Moodle

\begin{tabular}{|c|c|c|c|c|c|c|c|c|}
\hline \multirow[b]{2}{*}{ Item } & \multirow[b]{2}{*}{ Mean } & \multirow{2}{*}{$\begin{array}{l}\text { Standard } \\
\text { Deviation }\end{array}$} & \multicolumn{5}{|c|}{ Response \% } & \multirow{2}{*}{ Scale } \\
\hline & & & $\begin{array}{l}\text { Strongly } \\
\text { Agree }\end{array}$ & Agree & Neutral & Disagree & $\begin{array}{l}\text { Strongly } \\
\text { Disagree }\end{array}$ & \\
\hline ATU1 & 1.48 & 0.58 & 56 & 40 & 4 & 0 & 0 & Strongly Agree \\
\hline ATU2 & 1.46 & 0.58 & 58 & 38 & 4 & 0 & 0 & Strongly Agree \\
\hline BI1 & 1.36 & 0.56 & 68 & 28 & 4 & 0 & 0 & Strongly Agree \\
\hline $\mathrm{BI} 2$ & 1.34 & 0.56 & 70 & 26 & 4 & 0 & 0 & Strongly Agree \\
\hline $\mathrm{BI3}$ & 1.42 & 0.57 & 62 & 34 & 4 & 0 & 0 & Strongly Agree \\
\hline BI4 & 1.34 & 0.56 & 70 & 26 & 4 & 0 & 0 & Strongly Agree \\
\hline
\end{tabular}

explained in detailed, but rather the participants were just asked to get a 'feel' of the platform. This might be solved by proper training on Moodle. Despite the lack of deeper explanation of functionalities, participants acknowledged that their interaction with Moodle was clear, as shown by $96 \%$ and $94 \%$ of 
them both agreeing and strongly agreeing with PEOU3 and PEOU4 respectively and none disagreeing with both statements. This might be explained by the simple interface of Moodle and easy navigation tools. Majority of participants thus agree that they will find Moodle easy to use, as shown by $90 \%$ of them both agreeing and strongly agreeing (with mean of 1.82) with the statement PEOU7. Overall, the results in Table 5 show that after their interaction with Moodle, BUAN lecturers believe that it will not require a lot of effort in them operating Moodle, hence consider it easy to use. The statements in Table 4 are described as follows:

PEOU1: Learning to operate Moodle will be easy for me

PEOU2: I will find it easy to get Moodle to do what I want it to do

PEOU3: My interaction with Moodle was clear

PEOU4: I find Moodle flexible to interact with

PEOU5: It will be easier for me to become skilful at using Moodle

PEOU6: Moodle provides guidance in performing tasks

PEOU7: Overall, I will find Moodle easy to use.

\subsection{Attitude Toward Using Moodle}

The availability of resources, and training on these resources is not enough for a person to use the resources, hence in order for BUAN lecturers to use Moodle, their attitudes towards using the platform will have to be taken into consideration. To determine the participants' attitudes towards using Moodle, they were asked to rate their level of agreement with the following two statements:

ATU1: My attitude towards using Moodle make me intend to use it

ATU2: My attitude towards using Moodle makes me accept to use it

A 5 item Likert scale (i.e. $1=$ Strongly Agree, $2=$ Agree, 3 = Neutral, $4=$ Disagree and $5=$ Strongly Disagree) to rate their level of agreement on the above 2 statements was used. The statistical analysis results of this are shown in Table 6 below. According to the data, participants strongly agree with the 2 statements as shown by means of 0.58 for both. None of the participants disagreed that their attitudes towards Moodle will make them intend and accept the use the platform in teaching. Therefore, the results indicate that BUAN lecturer' attitudes point to them viewing Moodle as an attractive tool that they will be willing to use in their teaching.

\subsection{Behavioural Intention to Use Moodle}

After interacting with and getting an appreciation of Moodle from the pilot test set in the university, the lecturers knew whether they planned to use Moodle once it is properly set up and they have gone through the needed training. To see if indeed they had formed such plans, participants were subjected to 4 statements in which they checked their level of agreement with 4 items on their intention to use Moodle. These items were again tested using a 5 item Likert scale where $1=$ Strongly Agree, $2=$ Agree, $3=$ Neutral, $4=$ Disagree and $5=$ Strongly Disagree. The participants were asked to rate their level of agreement with the 4 statements. The results, in Table 6 above, show that $70 \%$ of lecturers strongly agree that they have intention of using Moodle, hence they will accept it if it is implemented at BUAN. TAM says if people perceive a technology useful, they will in turn form plans to use it. The results in Table 6 confirms this as $96 \%$ of participants both agree and strongly agree that their decision to intend to use Moodle is informed by their perception of the usefulness of Moodle. TAM also shows that attitude to use technology is a direct determinant of behavioural intention to use the same technology, and this study confirmed this as $96 \%$ of participants said their plan to intend to use Moodle is as a result of their attitude towards it. Although under TAM, perceived ease of use of technology has not been directly linked to behavioural intention to use it, this study showed that participants believe their perception on the effortlessness of using Moodle is a direct determinant of their intention to use the Moodle. Therefore, since BUAN lecturers perceive Moodle to be useful and not requiring much effort to use, and also having shown positive attitudes towards using it, they have plans to use it in execution of their duties once it is implemented at their university.

\section{Conclusions, Limitations and Recommendations}

This study largely confirms the findings of previous studies on the application of TAM in gauging the possible acceptance of technology. Established by this study, and other literature, PU and PEOU have positive effect on attitude of people towards using a technology. The results also indicate that PEOU is a direct determinant of PU. From BUAN lecturers' point of view, they find Moodle useful hence have formed plans to use it. Thus, this is consistent with TAM in that PU is found to have a positive influence on behavioural intention to use a technology. The lecturers' attitudes towards using Moodle have also been found to inform their intentions to use it. This is also in agreement with 
TAM, and match results from other literature, that attitude towards using a technology positively influence behavioural intention to use that particular technology. Although TAM does not indicate PEOU as a direct determinant of BI, our study has shown that PEOU is a critical driver of BI. If the lecturers find Moodle to be effortless to use, and that it brings along a lot of benefits, then they will form positive behaviours of integrating it into basic teaching at BUAN.

Several studies, such as [13], have shown that demographic characteristics can influence a person's acceptance of a new technology, and this study can be extended to investigate if lecturers' demographic factors do indeed influence their acceptance of Moodle platform. These may include variables such as age, gender, educational qualifications, experience of teaching in a tertiary level institution, teaching styles and cultural background, as these factors can explain why people behave the way they do. As is the case with all empirical research, this study has some limitations that should be considered when interpreting the results. The survey participants were lecturers from only one faculty of the university, that is, the Faculty of Agriculture. Most of the lecturers are trained in agriculture, and do not have much knowledge of technological developments. Hence, this will not reveal any differences between those with and those without prior training in technology. Other university faculties are not used as they are not yet developed and functional. BUAN is a public university, and the fact that this study does not survey lecturers from private universities might not be fully representative of higher education institutions in Botswana. Nevertheless, the results of this study should be a very good starting point for research on acceptance of technology by lecturers in higher institutions of learning in Botswana.

\section{Acknowledgements}

The authors would like to thank Mr G. P. Nthoiwa of BUAN's Basic Sciences department who helped with correlation analysis.

\section{References}

[1] M. Moakofhi, O. Leteane, T. Phiri, T. Pholele, and P. Sebalatlheng, "Challenges of introducing e-learning at Botswana University of Agriculture and Natural Resources: Lecturers' perspective", International Journal of Education and Development using ICT, vol. 13, no. 2, 2017.

[2] A.A. AlQudah, "Accepting Moodle by academic staff at the University of Jordan: Applying and extending TAM in technical support factors", European Scientific Journal, ESJ, vol. 10, no. 8, 2014.
[3] M. Masrom, "Technology acceptance model and elearning”, Technology, vol. 21, no. 24, 2007, pp. 81.

[4] C. Costa, H. Alvelos, and L. Teixeira, "The use of Moodle e-learning platform: a study in a Portuguese University", Procedia Technology, vol. 5, 2012, pp. 334343.

[5] B. Šumak, M. Heričko, M. Pušnik, and G. Polančič, "Factors affecting acceptance and use of Moodle: An empirical study based on TAM", Informatica, vol. 35, no. 1,2011

[6] S.Y. Park, "An analysis of the technology acceptance model in understanding university students' behavioral intention to use e-learning", Educational Technology \& Society, vol. 12 , no. 3, 2009, pp. 150-162.

[7] K.S. Hong, K.W. Lai, and D. Holton, "Students' satisfaction and perceived learning with a web-based course", Educational Technology \& Society, vol. 6, no. 1, 2003, pp. 116-124.

[8] J. Cole, and H. Foster, Using Moodle: Teaching with the popular open source course management system, O'Reilly Media, Inc., 2007.

[9] D. Bremer, and R. Bryant, "A Comparison of two learning management systems: Moodle vs Blackboard", In Proceedings of the 18th Annual Conference of the National Advisory Committee on Computing Qualifications, 2005, pp. 135-139.

[10] M.M. Motshegwe, and P.Y. Thomas, "A feasibility study of Moodle: The case of University of Botswana", Lonaka Journal of Learning and Teaching, 2012.

[11] F.D. Davis, "Perceived usefulness, perceived ease of use, and user acceptance of information technology", MIS Quarterly, 1989, pp. 319-340.

[12] P.Y. Chau, and P.J.H. Hu, "Investigating healthcare professionals' decisions to accept telemedicine technology: an empirical test of competing theories", Information \& Management, vol. 39, no. 4, 2002, pp. 297-311.

[13] D. Gefen, and D. W. Straub, "Gender differences in the perception and use of e-mail: An extension to the technology acceptance model”, MIS Quarterly, 1997, pp. $389-400$.

[14] A.L. Lederer, D.J. Maupin, M.P. Sena, and Y. Zhuang, "The technology acceptance model and the World Wide Web", Decision Support Systems, vol. 29, no. 3, 2000, pp. 269-282.

[15] M.G. Morris, and A. Dillon, "How user perceptions influence software use", IEEE Software, vol. 14, no. 4, 1997 , pp. 58-65.

[16] I. Lule, T.K. Omwansa, and T.M. Waema, "Application of technology acceptance model (TAM) in m-banking adoption in Kenya", International Journal of Computing \& ICT Research, vol. 6, no. 1, 2012. 
[17] M.K. Lee, C.M. Cheung, and Z. Chen, "Acceptance of Internet-based learning medium: the role of extrinsic and intrinsic motivation", Information \& Management, vol. 42, no. 8, 2005, pp. 1095-1104.

[18] A. Al-Adwan, A. Al-Adwan, and J. Smedley, "Exploring students' acceptance of e-learning using Technology Acceptance Model in Jordanian universities", International Journal of Education and Development using ICT, vol. 9, no. 2, 2013.

[19] K.T. Wong, “Understanding Student Teachers' Behavioural Intention to Use Technology: Technology Acceptance Model (TAM) Validation and Testing”, Online Submission, vol. 6, no. 1, 2013, pp. 89-104.

[20] C.C. Chang, C.F. Yan, and J.S. Tseng, "Perceived convenience in an extended technology acceptance model: Mobile technology and English learning for college students", Australasian Journal of Educational Technology, vol. 28, no. 5, 2012. 